\title{
Prophylactic plasma and platelet transfusion in the critically III patient: just useless and expensive or even harmful?
}

\author{
Klaus Görlinger ${ }^{1,2^{*}}$ and Fuat H. Saner ${ }^{3}$
}

\begin{abstract}
It is still common practice to correct abnormal standard laboratory test results, such as increased INR or low platelet count, prior to invasive interventions, such as tracheostomy, central venous catheter insertion or liver biopsy, in critically ill patients. Data suggest that $30-90 \%$ of plasma transfused for these indications is unnecessary and puts the patient at risk. Plasma transfusion is associated with a high risk of transfusion-associated adverse events such as transfusion-associated circulatory overload (TACO), transfusion-related lung injury (TRALI), transfusion-related immunomodulation (TRIM), and anaphylaxis/allergic reactions. Therefore, the avoidance of inappropriate plasma transfusion bears a high potential of improving patient outcomes. The prospective study by Durila et al., published recently in BMC Anesthesiology, provides evidence that tracheostomies can be performed without prophylactic plasma transfusion and bleeding complications in critically ill patients despite increased INR in case of normal thromboelastometry (ROTEM) results. Thromboelastometry-based restrictive transfusion management helped avoid unnecessary plasma and platelet transfusion, and should reduce the incidence of transfusion-related adverse events and transfusion-associated hospital costs. Therefore, the authors believe that thromboelastometry-based strategies should be implemented to optimize patient blood management in perioperative medicine.
\end{abstract}

Keywords: Critically ill, Tracheostomy, INR, Thromboelastometry, Prophylactic plasma transfusion, Patient blood management

\section{Background}

Thirty to Ninety percent of plasma transfused perioperative or at the ICU has to be considered as inappropriate [1-6]. Here, plasma transfusion has been considered as inappropriate in patients with normal INR $(<1.5)$, transfused as a prophylaxis in non-bleeding patients with mildly abnormal coagulation tests, and transfused in an ineffective dose $(<10 \mathrm{~mL} / \mathrm{kg}$ bw). Post-transfusion corrections of INR are consistently small unless the pre-transfusion INR is only mildly deranged $(<2.5)$ [7]. Notably, the most frequent transfused dose of FFP is two to four units, which has been shown to be ineffective to improve coagulation in several studies [6-10]. A systematic review of the literature including 80 RCTs showed no consistent evidence of

\footnotetext{
* Correspondence: klaus@goerlinger.net

'Department of Anesthesiology and Intensive Care Medicine, University Hospital Essen, Essen, Germany

${ }^{2} \mathrm{Tem}$ International $\mathrm{GmbH}$, Munich, Germany

Full list of author information is available at the end of the article
}

significant benefit for prophylactic and therapeutic use of FFP across a range of indications evaluated [11]. Accordingly, Müller et al. [12] could not show any differences in bleeding complications in critically ill patients undergoing an invasive procedure in their RCT, regardless whether FFP was prophylactically administered or not. In trauma, even with a :PRBC transfusion ratio of 1:1 it took in mean $14.8 \mathrm{~h}$ to correct an INR of $1.8 \mathrm{ad}$ admission to a INR of $<$ 1.5 at the ICU [13].

On the other hand, plasma transfusion is associated with a high risk of transfusion-associated adverse events such as transfusion-associated circulatory overload (TACO), transfusion-related lung injury (TRALI), transfusionrelated immunomodulation (TRIM), and anaphylaxis/ allergic reactions. TRIM results in a significant increase in the incidence of nosocomial infections and sepsis in critically ill surgical patients transfused with FFP (RR, 2.99; $95 \%$ CI, 2.28-3.93) [14]. Still, TRALI is the leading cause of transfusion-related death in the US with an incidence of 
TRALI/possible TRALI of 1.4 to $3.0 \%$ of adult patients undergoing surgery and receiving transfusion [15]. Furthermore, TACO is a leading cause of transfusion-related fatalities in the US with an incidence of $3-5.5 \%$ in transfused patients [16]. This is in line with the SHOT report 2013, reporting TACO as the leading cause of transfusionrelated death (12 of 22 or $54.5 \%$ ) and major morbidity (43 of 143 or $30.1 \%$ ) in the UK [17]. Accordingly, plasma is the allogeneic blood product with the highest impact on increased long-term mortality (HR, 1.060 per unit transfused; $P<0.001)$ in patients undergoing coronary artery bypass surgery [18]. Furthermore, in non-massively transfused trauma patients $(<10 \mathrm{U}$ PRBC within $12 \mathrm{~h}$ of admission), plasma administration was associated with a substantial increase in complications, in particular ARDS (12-fold), with no improvement in survival. An increase in multiple organ dysfunction (6-fold), pneumonia (4-fold), and sepsis (4-fold) was likewise seen as increasing volumes of plasma ( $>6 \mathrm{U}$ ) were transfused [19]. In another US trauma study, exposure to ABO-compatible (pre-thawed "universal donor" plasma) versus $\mathrm{ABO}$-identical plasma resulted in an increase in overall complications $(53.5 \%$ vs $40.5 \%, P=0.002)$, in particular ARDS $(19.4 \%$ vs $9.2 \%$, $P=0.0011)$ and sepsis ( $38.0 \%$ vs $28.9 \%, P=0.02)$. There was a stepwise increase in the complication rate as exposure increases (reaching $70.0 \%$ for patients receiving more than $6 \mathrm{U}$; these patients also had a 4-fold increase in ARDS) [20]. This is in line with a study in 86,082 Swedish patents receiving their first plasma transfusion and had a follow up of 14 days. Here, transfusion of five or more units of AB0-compatible but non-identical plasma was associated with an increased mortality (RR, 1.15; $95 \% \mathrm{CI}$, 1.02-1.29) compared to recipients of only AB0-identical plasma [21]. Therefore, the avoidance of inappropriate plasma transfusion has a high potential of improving patient outcomes.

\section{Main text}

Durila et al. [22] assessed in their prospective study, published recently in BMC Anesthesiology, whether tracheostomy in 119 septic and non-septic ICU patients can be performed without bleeding complications in case of normal thromboelastometry (ROTEM) results (EXTEM CT (coagulation time)) despite increased INR. Normal INR $(\leq 1.2)$ was found in $64(54 \%)$ patients, while increased INR (>1.2) was found in $55(46 \%)$ patients. Patients with INR $\geq 1.3$ (median INR, 1.48; range, 1.3-1.84) were further assessed by thromboelastometry. Despite prolonged INR, thromboelastometry results were in normal ranges in all cases except one. With normal thromboelastometry, tracheostomy was performed safely without FFP transfusion and any bleeding complication. Here, thromboelastometry analysis avoided unnecessary FFP transfusion in $98 \%(54 / 55)$ critically ill patients with increased INR.
Since their former practice was to transfuse four units of FFP prophylactically prior to tracheostomy in patients with an INR $>1.2$, implementation of thromboelastometry testing reduced FFP transfusion from 220 to 4 units in this setting without any increase in bleeding complications. Their study provides a valuable contribution to the increasing evidence that invasive interventions, such as tracheostomy, central venous line insertion or liver biopsy, can be performed without prophylactic FFP or platelet transfusion in critically ill patients with abnormal standard laboratory tests, such as INR or platelet count, in case of normal thromboelastometry results. This viscoelastic method can help physicians to avoid unnecessary transfusion and corresponding transfusion-related adverse events.

\section{Discussion}

Standard laboratory coagulation tests (SLTs), such as PT/INR and platelet count, are still frequently used to assess coagulopathy and to guide hemostatic interventions. However, Haas et al. recently reviewed the evidence for the usefulness of SLTs to assess coagulopathy and to guide bleeding management in the perioperative and massive bleeding setting. Evidence for the usefulness of SLTs was found in only three prospective trials, investigating a total of 108 patients, whereby microvascular bleeding was a rare finding. No data from RCTs supported the use of SLTs. In contrast, numerous investigations have challenged the reliability of SLTs to assess coagulopathy or guide bleeding management [23]. In another study, Haas et al. [24] demonstrated that PT/INR and aPTT tests overestimate the underlying coagulation factor deficiency if more than one factor is reduced, which typically occurs in dilutional coagulopathy. Thus, impaired PT/INR and aPTT values are a very common and early finding during hemodilution and intraoperative bleeding, and therefore, decision-making based on PT/ INR and aPTT may lead to considerable over-transfusion of FFP and other blood products. Nevertheless, increased INR values correlate quite well with EXTEM CT in warfarin-treated patients and healthy controls (Spearman rho $=0.87$ ). Here, EXTEM CT has a sensitivity and specificity of 0.89 and 1.00 , respectively, to detect elevated INR above 1.2 , with a positive and negative predictive value of 1.00 and 0.88 , respectively [25]. However, the correlation between INR and EXTEM CT seem to be different in other setting, such as dilutional coagulopathy, cirrhosis, sepsis, and patients with extracorporeal assist devices [24, 26-28]. Here, tissue factor-expression on circulating monocytes can result in a shortening of CT in whole blood viscoelastic tests whereas plasmatic SLTs are unable to detect this effect [29]. In contrast to EXTEM CT, the false-negative rate of kaolin-TEG and rapid-TEG (kaolin plus tissue factor activation) for detecting warfarin coagulopathy with either test is clinically unacceptable [30]. This 
may be due to the fact that the intrinsic pathway is activated in these tests.

Similar considerations have been made regarding the predictive value of platelet count versus thromboelastometric clot firmness for bleeding after invasive interventions. Weigand et al. [31] demonstrated that coagulation disorders with altered INR $(\geq 1.5)$ or platelet count $\left(\leq 50 \times 10^{9} / \mathrm{L}\right)$ did not increase the risk of significant bleeding when inserting a central venous catheter. Zeidler et al. [32] demonstrated in their retrospective singlecenter analysis of 604 central venous catheter insertions in 193 patients with acute leukemia that only patients with platelet counts of less than $20 \times 10^{9} / \mathrm{L}$ were at higher risk of bleeding compared to patients with platelet counts of $100 \times 10^{9} / \mathrm{L}$ or more. However, Greene et al. [33] demonstrated that thromboelastometric clot firmness (EXTEM or INTEM A10 or MCF) is superior to platelet count in predicting bleeding in pediatric patients with immune thrombocytopenia (ITP) and severe thrombocytopenia $\left(<30 \times 10^{9} / \mathrm{L}\right)$. Superiority of thromboelastometry maximum clot firmness (MCF) compared to platelet count in predicting bleeding in patients with hematological malignancies has recently been confirmed in the prospective observational ATHENA study [34]. Further studies confirmed that EXTEM clot firmness (A10 and MCF) can be used to assess the efficacy of prophylactic platelet transfusion before insertion of a central venous catheter in patients with bone morrow failure and in thrombocytopenic children undergoing chemotherapy $[35,36]$. Furthermore, Fayed et al. [37] reported that a thromboelastometryguided transfusion protocol in patients undergoing liver transplantation can avoid $75 \%$ of platelet transfusions in patients with a platelet count $<50 \times 10^{9} / \mathrm{L}$ without increased bleeding rate. Therefore, thromboelastometry clot firmness (EXTEM or INTEM A10 or MCF) should be considered in addition to EXTEM CT in particular in critically ill patients with thrombocytopenia undergoing tracheostomy. However, drug-, trauma- or sepsis-induced changes in platelet function cannot be detected by standard viscoelastic tests, such as ROTEM or TEG. This is an important limitation of viscoelastic testing since the high amounts of thrombin generated in these test systems can overwhelm the inhibition of other platelet activation pathways, such as the arachidonic acid, collagen, serotonin, or ADP pathway. This diagnostic gap can be closed by pointof-care platelet function testing such as whole blood impedance aggregometry (Multiplate or ROTEM platelet) which is much more sensitive to these effects [28, 38-40]. Platelet dysfunction cannot only be induced by so call "antiplatelet drugs" but also by a lot of other drugs used for treatment in critically ill patients such as non-steroidal anti-inflammatory drugs (NSAIDs), selective serotonin release inhibitors (SSRIs), $\beta$-lactam antibiotics, as well as cardiovascular and lipid-lowering drugs $[41,42]$. In particular combination of these drugs can induce severe platelet dysfunction [42, 43].

Accordingly, point-of-care-guided bleeding management algorithms, using thromboelastometry and impedance aggregometry, have been shown to be effective in reducing transfusion requirements in cardiovascular surgery, liver transplantation, trauma, obstetrics, and other critically ill patients [44-48]. Here, transfusion requirements for FFP, PRBC, and platelets could be reduced by 70-90\%, 10-60\%, and 20-70\%, respectively [49]. In addition, this is associated with significant cost-savings [48-51]. Furthermore, the incidence of massive transfusion, revision surgery, TACO, acute lung injury, multiple organ failure, nosocomial infection and sepsis, as well as thromboembolic events could be reduced significantly $[44,47-53]$. The later can be explained by the high predictive value of thromboelastometry for postoperative complications after major non-cardiac surgery (ROC $\mathrm{AUC}=0.751$ for INTEM A10), which allows for defining a therapeutic window to stop bleeding without increased risk of thromboembolic events [54]. Similar results have been reported for cardiovascular patients [55].

\section{Conclusions}

The prospective study by Durila et al. [22] provides further evidence that invasive interventions such as tracheostomy can be performed without prophylactic plasma transfusion and bleeding complications in critically ill patients with increased INR in case of normal thromboelastometry results. thromboelastometry-based restrictive transfusion management, avoiding unnecessary plasma and platelet transfusion, can reduce the incidence of transfusion-related adverse events and transfusion-associated hospital costs. Therefore, the authors believe that thromboelastometrybased strategies should be implemented to optimize patient blood management in perioperative medicine.

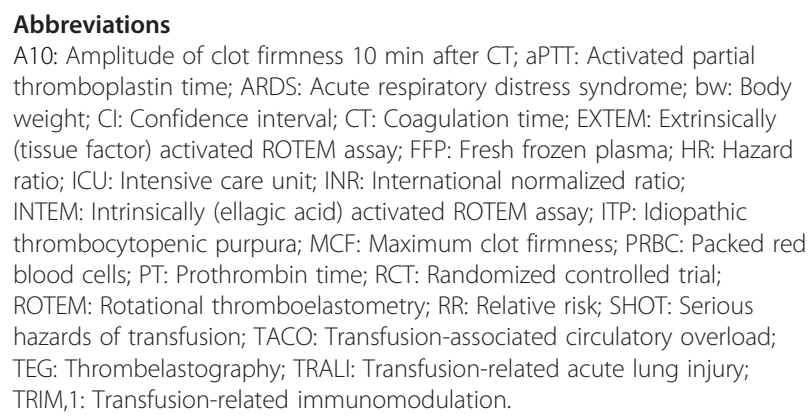

Competing interests

Klaus Görlinger works as the Medical Director of Tem International since July 2012. Fuat H. Saner declares no competing interests.

Authors' contributions

Both authors read and approved the final manuscript 


\section{Authors' information}

Commentary article: Durila M, Lukas P, Astraverkhava M, Berousek J, Zabrodsky M, Vymazal T. Tracheostomy in intensive care unit patients can be performed without bleeding complications in case of normal thromboelastometry results (EXTEM CT) despite increased PT-INR: a prospective pilot study. BMC Anesthesiology 2015, in press.

\section{Author details}

${ }^{1}$ Department of Anesthesiology and Intensive Care Medicine, University Hospital Essen, Essen, Germany. ${ }^{2}$ Tem International GmbH, Munich, Germany. ${ }^{3}$ Department of General, Visceral and Transplant Surgery, University Hospital Essen, Essen, Germany.

\section{Received: 1 June 2015 Accepted: 1 June 2015}

\section{Published online: 09 June 2015}

\section{References}

1. Arnold DM, Lauzier F, Whittingham H, Zhou Q, Crowther MA, McDonald E, et al. A multifaceted strategy to reduce inappropriate use of frozen plasma transfusions in the intensive care unit. J Crit Care. 2011;26:636.e7-636.e13.

2. Stanworth SJ, Grant-Casey J, Lowe D, Laffan M, New H, Murphy MF, et al. The use of fresh-frozen plasma in England: high levels of inappropriate use in adults and children. Transfusion. 2011;51:62-70.

3. Tinmouth AT, Mclntyre L. The conundrum of persistent inappropriate use of frozen plasma. Crit Care. 2011;15:160.

4. Pybus S, MacCormac A, Houghton A, Martlew V, Thachil J. Inappropriateness of fresh frozen plasma for abnormal coagulation tests. J R Coll Physicians Edinb. 2012:42:294-300.

5. Visser A, Geldenhuys A, Du Preez S, Van de Vyver A. Fresh-frozen plasma use in a South African tertiary hospital. S Afr Med J. 2012;102:366-7.

6. Tinmouth A, Thompson T, Arnold DM, Callum JL, Gagliardi K, Lauzon D, et al. Utilization of frozen plasma in Ontario: a provincewide audit reveals a high rate of inappropriate transfusions. Transfusion. 2013;53:2222-9.

7. Stanworth SJ, Walsh TS, Prescott RJ, Lee RJ, Watson DM, Wyncoll D. Intensive Care Study of Coagulopathy (ISOC) investigators. A national study of plasma use in critical care: clinical indications, dose and effect on prothrombin time. Crit Care. 2011;15:R108.

8. Dara SI, Rana R, Afessa B, Moore SB, Gajic O. Fresh frozen plasma transfusion in critically ill medical patients with coagulopathy. Crit Care Med. 2005;33:2667-71.

9. Abdel-Wahab OI, Healy B, Dzik WH. Effect of fresh-frozen plasma transfusion on prothrombin time and bleeding in patients with mild coagulation abnormalities. Transfusion. 2006;46:1279-85.

10. Holland $L L$, Brooks JP. Toward rational fresh frozen plasma transfusion: The effect of plasma transfusion on coagulation test results. Am J Clin Pathol. 2006;126:133-9.

11. Yang L, Stanworth S, Hopewell S, Doree C, Murphy M. Is fresh-frozen plasma clinically effective? An update of a systematic review of randomized controlled trials. Transfusion. 2012;52:1673-86.

12. Müller MC, Arbous MS, Spoelstra-de Man AM, Vink R, Karakus A, Straat M, et al. Transfusion of fresh-frozen plasma in critically ill patients with a coagulopathy before invasive procedures: a randomized clinical trial (CME). Transfusion. 2015;55:26-35.

13. Gonzalez EA, Moore FA, Holcomb JB, Miller CC, Kozar RA, Todd SR, et al. Fresh frozen plasma should be given earlier to patients requiring massive transfusion. J Trauma. 2007;62:112-9.

14. Sarani B, Dunkman WJ, Dean L, Sonnad S, Rohrbach Jl, Gracias VH. Transfusion of fresh frozen plasma in critically ill surgical patients is associated with an increased risk of infection. Crit Care Med. 2008;36:1114-8.

15. Clifford L, Jia Q, Subramanian A, Yadav H, Wilson GA, Murphy SP, et al. Characterizing the epidemiology of postoperative transfusion-related acute lung injury. Anesthesiology. 2015;122:12-20.

16. Clifford L, Jia Q, Yadav H, Subramanian A, Wilson GA, Murphy SP, et al. Characterizing the epidemiology of perioperative transfusion-associated circulatory overload. Anesthesiology. 2015;122:21-8.

17. Bolton-Maggs PH. Bullet points from SHOT: key messages and recommendations from the Annual SHOT Report 2013. Transfus Med. 2014;24:197-203.

18. Bjursten H, Dardashti A, Ederoth $P$, Brondén B, Algotsson L. Increased long-term mortality with plasma transfusion after coronary artery bypass surgery. Intensive Care Med. 2013;39:437-44
19. Inaba K, Branco BC, Rhee P, Blackbourne LH, Holcomb JB, Teixeira PG, et al. Impact of plasma transfusion in trauma patients who do not require massive transfusion. J Am Coll Surg. 2010;210:957-65

20. Inaba K, Branco BC, Rhee P, Holcomb JB, Blackbourne LH, Shulman I, et al. Impact of $\mathrm{ABO}$-identical vs $\mathrm{ABO}$-compatible nonidentical plasma transfusion in trauma patients. Arch Surg. 2010;145:899-906.

21. Shanwell A, Andersson TM, Rostgaard K, Edgren G, Hjalgrim H, Norda R, et al. Post-transfusion mortality among recipients of $\mathrm{ABO}$-compatible but non-identical plasma. Vox Sang. 2009;96:316-23.

22. Durila M, Lukas P, Astraverkhava M, Berousek J, Zabrodsky M, Vymazal T. Tracheostomy in intensive care unit patients can be performed without bleeding complications in case of normal thromboelastometry results (EXTEM CT) despite increased PT-INR: a prospective pilot study. BMC Anesthesiology. 2015; in press.

23. Haas T, Fries D, Tanaka KA, Asmis L, Curry NS, Schöchl H. Usefulness of standard plasma coagulation tests in the management of perioperative coagulopathic bleeding: is there any evidence? Br J Anaesth. 2015;114:217-24.

24. Haas T, Spielmann N, Mauch J, Madjdpour C, Speer O, Schmugge M, et al. Comparison of thromboelastometry $\left(\mathrm{ROTEM}^{\oplus}\right)$ with standard plasmatic coagulation testing in paediatric surgery. Br J Anaesth. 2012;108:36-41.

25. Schmidt DE, Holmström M, Majeed A, Näslin D, Wallén H, Ågren A Detection of elevated INR by thromboelastometry and thromboelastography in warfarin treated patients and healthy controls. Thromb Res. 2015;135:1007-11.

26. Saner FH, Gieseler RK, Akız H, Canbay A, Görlinger K. Delicate balance of bleeding and thrombosis in end-stage liver disease and liver transplantation. Digestion. 2013;88:135-44.

27. Adamzik M, Eggmann M, Frey UH, Görlinger K, Bröcker-Preuss M, Marggraf $\mathrm{G}$, et al. Comparison of thromboelastometry with procalcitonin, interleukin 6, and C-reactive protein as diagnostic tests for severe sepsis in critically ill adults. Crit Care. 2010;14:R178.

28. Görlinger K, Bergmann L, Dirkmann D. Coagulation management in patients undergoing mechanical circulatory support. Best Pract Res Clin Anaesthesiol. 2012;26:179-98.

29. Adamzik M, Schäfer S, Frey UH, Becker A, Kreuzer M, Winning S, et al. The NFKB1 promoter polymorphism (-94ins/delATTG) alters nuclear translocation of NF-KB1 in monocytes after lipopolysaccharide stimulation and is associated with increased mortality in sepsis. Anesthesiology. 2013;118:123-33.

30. Dunham CM, Rabel C, Hileman BM, Schiraldi J, Chance EA, Shima MT, et al. TEG $^{\circledast}$ and RapidTEG ${ }^{\circledR}$ are unreliable for detecting warfarin-coagulopathy: a prospective cohort study. Thromb J. 2014;12:4.

31. Weigand K, Encke J, Meyer FJ, Hinkel UP, Munder M, Stremmel W, et al. Low levels of prothrombin time (INR) and platelets do not increase the risk of significant bleeding when placing central venous catheters. Med Klin (Munich). 2009;104:331-5

32. Zeidler K, Arn K, Senn O, Schanz U, Stussi G. Optimal preprocedural platelet transfusion threshold for central venous catheter insertions in patients with thrombocytopenia. Transfusion. 2011;51:2269-76.

33. Greene LA, Chen S, Seery C, Imahiyerobo AM, Bussel JB. Beyond the platelet count: immature platelet fraction and thromboelastometry correlate with bleeding in patients with immune thrombocytopenia. Br J Haematol. 2014;166:592-600.

34. Estcourt LJ, Stanworth SJ, Harrison P, Powter G, McClure M, Murphy MF, et al. Prospective observational cohort study of the association between thromboelastometry, coagulation and platelet parameters and bleeding in patients with haematological malignancies- the ATHENA study. $\mathrm{Br} J$ Haematol. 2014;166:581-91.

35. Kander T, Tanaka KA, Norström E, Persson J, Schött U. The effect and duration of prophylactic platelet transfusions before insertion of a central venous catheter in patients with bone marrow failure evaluated with point-of-care methods and flow cytometry. Anesth Analg. 2014;119:882-90.

36. Ziegler B, Solomon C, Cadamuro J, Jones N. Thromboelastometric Monitoring of the Hemostatic Effect of Platelet Concentrates Transfusion in Thrombocytopenic Children Undergoing Chemotherapy. Clin Appl Thromb Hemost. 2014. [Epub ahead of print]

37. Fayed NA, Abdallah AR, Khalil MK, Marwan IK. Therapeutic rather than prophylactic platelet transfusion policy for severe thrombocytopenia during liver transplantation. Platelets. 2014;25:576-86.

38. Görlinger K, Jambor C, Hanke AA, Dirkmann D, Adamzik M, Hartmann M, et al. Perioperative coagulation management and control of platelet 
transfusion by point-of-care platelet function analysis. Transfus Med Hemother. 2007;34(6):396-411.

39. Solomon C, Traintinger S, Ziegler B, Hanke A, Rahe-Meyer N, Voelckel W, et al. Platelet function following trauma. A multiple electrode aggregometry study. Thromb Haemost. 2011;106:322-30.

40. Adamzik M, Görlinger K, Peters J, Hartmann M. Whole blood impedance aggregometry as a biomarker for the diagnosis and prognosis of severe sepsis. Crit Care. 2012;16:R204.

41. Konkle BA. Acquired disorders of platelet function. Hematol Am Soc Hematol Educ Program. 2011;2011:391-6.

42. Scharf RE. Drugs that affect platelet function. Semin Thromb Hemost. 2012;38:865-83.

43. Van Cann EM, Koole R. An emergency tracheotomy in case of airway compromise after post-operative bleeding associated with the use of an antidepressant. Ned Tijdschr Tandheelkd. 2009:116(10):544-6.

44. Haas T, Görlinger K, Grassetto A, Agostini V, Simioni P, Nardi G, et al. Thromboelastometry for guiding bleeding management of the critically ill patient: a systematic review of the literature. Minerva Anestesiol. 2014;80:1320-35.

45. Corredor C, Wasowicz M, Karkouti K, Sharma V. The role of point-of-care platelet function testing in predicting postoperative bleeding following cardiac surgery: a systematic review and meta-analysis. Anaesthesia. 2015;70:715-31.

46. Kirchner C, Dirkmann D, Treckmann JW, Paul A, Hartmann M, Saner FH, et al. Coagulation management with factor concentrates in liver transplantation: a single-center experience. Transfusion. 2014;54:2760-8.

47. Karkouti K, McCluskey SA, Callum J, Freedman J, Selby R, Timoumi T, et al. Evaluation of a novel transfusion algorithm employing point-of-care coagulation assays in cardiac surgery: a retrospective cohort study with interrupted time-series analysis. Anesthesiology. 2015;122:560-70.

48. Pearse BL, Smith I, Faulke D, Wall D, Fraser JF, Ryan EG, et al. Protocol guided bleeding management improves cardiac surgery patient outcomes. Vox Sang. 2015. doi: 10.1111/vox.12279. [Epub ahead of print]

49. Görlinger K, Fries D, Dirkmann D, Weber CF, Hanke AA, Schöchl H Reduction of Fresh Frozen Plasma Requirements by Perioperative Point-of-Care Coagulation Management with Early Calculated Goal-Directed Therapy. Transfus Med Hemother. 2012;39:104-13.

50. Görlinger K, Dirkmann D, Hanke AA, Kamler M, Kottenberg E, Thielmann M, et al. First-line therapy with coagulation factor concentrates combined with point-of-care coagulation testing is associated with decreased allogeneic blood transfusion in cardiovascular surgery: a retrospective, single-center cohort study. Anesthesiology. 2011;115:1179-91.

51. Weber CF, Görlinger $K$, Meininger D, Herrmann E, Bingold T, Moritz A, et al. Point-of-care testing: a prospective, randomized clinical trial of efficacy in coagulopathic cardiac surgery patients. Anesthesiology. 2012;117:531-47.

52. Nienaber U, Innerhofer $P$, Westermann I, Schöchl H, Attal R, Breitkopf R, et al. The impact of fresh frozen plasma vs coagulation factor concentrates on morbidity and mortality in trauma-associated haemorrhage and massive transfusion. Injury. 2011;42:697-701.

53. Mallaiah S, Barclay P, Harrod I, Chevannes C, Bhalla A. Introduction of an algorithm for ROTEM-guided fibrinogen concentrate administration in major obstetric haemorrhage. Anaesthesia. 2015;70:166-75.

54. Hincker A, Feit J, Sladen RN, Wagener G. Rotational thromboelastometry predicts thromboembolic complications after major non-cardiac surgery. Crit Care. 2014;18:549.

55. Dimitrova-Karamfilova A, Patokova Y, Solarova T, Petrova I, Natchev G. Rotational thromboelastography for assessment of hypercoagulation and thrombosis in patients with cardiovascular disease. J Life Sci. 2012;6:28-35.

\section{Submit your next manuscript to BioMed Central and take full advantage of:}

- Convenient online submission

- Thorough peer review

- No space constraints or color figure charges

- Immediate publication on acceptance

- Inclusion in PubMed, CAS, Scopus and Google Scholar

- Research which is freely available for redistribution

Submit your manuscript at www.biomedcentral.com/submit 